\title{
-
}

RESEARCH AND EDUCATION

\section{Effect of surface treatments on repair with composite resin of a partially monoclinic phase transformed yttrium-stabilized tetragonal zirconia}

\author{
Beatriz Regalado Galvão Ribeiro, DDS, MSc, ${ }^{a}$ Marilia Regalado Galvão Rabelo Caldas, DDS, MSc, PhD, \\ Antonio Alves Almeida Jr, DDS, MSc, PhD, ${ }^{c}$ Renata Garcia Fonseca, DDS, MSc, PhD, ${ }^{d}$ and \\ Gelson Luis Adabo, DDS, MSc, $\mathrm{PhD}^{\mathrm{e}}$
}

Chipping has been considered the most frequent technical failure in yttrium-stabilized tetragonal zirconia polycrystal (Y-TZP) ceramic restorations. ${ }^{1-3}$ Another concern regarding these restorations is the adhesive failure between the core and the porcelain veneer, known as delamination, when core exposure occurs. ${ }^{1-3}$

Replacement of these restorations is expensive and time consuming, but depending on the extent of the fracture, intraoral repair with composite resin may be feasible. ${ }^{4,5}$ However, Y-TZP ceramic is almost inert, with low surface energy and wettability 6,7 and resists conventional etching with hydrofluoric acid. Furthermore, silane coupling agents are not effective with zirconia.

To improve the bond strength at the resin-Y-TZP interface, surface treatments that provide micromechanical retention and chemical bonding have been proposed. ${ }^{8}$ These include airborne-particle abrasion (APA) with aluminum 2018;119:286-291)

\begin{abstract}
Statement of problem. Studies of composite resin repairs of yttrium-tetragonal zirconia polycrystal (Y-TZP) are usually performed in its tetragonal phase, but it may be partially transformed into a monoclinic phase in a clinical fracture.

Purpose. The purpose of this in vitro study was to evaluate the effect of airborne-particle abrasion (APA) and a bonding agent on the shear bond strength (SBS) between a composite resin and hydrothermally aged Y-TZP.

Material and methods. Specimens $(7.0 \times 7.0 \times 1.7 \mathrm{~mm}, \mathrm{~N}=112)$ of $\mathrm{Y}$-TZP Lava were obtained, and $50 \%$ were aged in an autoclave at $134^{\circ} \mathrm{C}$ at $300 \mathrm{kPa}$ for 8 hours. The surfaces were treated with APA $50-\mu \mathrm{m} \mathrm{Al}_{2} \mathrm{O}_{3}$ particles (ALU) or Rocatec Soft $(30 \mu \mathrm{m})$ (ROC) followed by Clearfil SE Bond Primer (10-methacryloyloxydecyl dihydrogen phosphate [10-MDP]) plus Clearfil porcelain bond activator (3-methacryloxypropyl-trimethoxy silane [3-MPS]) (CLE) or RelyX Ceramic Primer plus a layer of RelyX U100 adhesive-resin cement (REL). Composite resin cylinders were built on the Y-TZP treated surfaces. After thermocycling ( 6000 cycles, $5^{\circ} \mathrm{C}$ and $55^{\circ} \mathrm{C}$, 30-second dwell time), an SBS test was carried out $(n=14)$. Data were analyzed by 3 -way ANOVA and the Tukey honest significant differences test $(\alpha=.05)$. The failure mode was analyzed.
\end{abstract}

Results. The 3-way ANOVA was not significant for aging $(P>.05)$, but the APA $(P<.001)$, bonding agent $(P<.001)$, and their interaction $(P<.001)$ were significant. APA with ALU or ROC did not influence the SBS of the groups bonded with CLE, but the REL APA with ROC provided higher SBS. The failure mode was adhesive for all specimens.

Conclusions. Adhesion was not different on monoclinic partially transformed Y-TZP. The APA with ROC followed by REL was the most effective treatment for repairing Y-TZP. (J Prosthet Dent

oxide $\left(\mathrm{Al}_{2} \mathrm{O}_{3}\right)$ particles or tribochemical silica coating (Rocatec Soft, Rocatec Plus), laser irradiation, and selective infiltration etching. ${ }^{8-16}$ Chemical bonding with silanes and primers containing functional monomers have also been

\footnotetext{
aDoctoral student, Department of Dental Materials and Prosthodontics, São Paulo State University (UNESP), School of Dentistry, São Paulo, Brazil.

${ }^{\mathrm{b}}$ Associate Professor, School of Dentistry, Federal University of Rio Grande do Norte, Grande do Norte, Brazil.

${ }^{c}$ Associate Professor, School of Dentistry, University of Tiradentes, Sergipe, Brazil.

${ }^{\mathrm{d} A s s o c i a t e}$ Professor, Department of Dental Materials and Prosthodontics, São Paulo State University, School of Dentistry, São Paulo, Brazil.

eFull Professor, Department of Dental Materials and Prosthodontics, São Paulo State University, School of Dentistry, São Paulo, Brazil.
} 


\section{Clinical Implications}

The Y-TZP tetragonal phase may be partially transformed into the monoclinic over time in clinical conditions because of aging phenomena, but does not influence the bonding of the resin-based materials.

evaluated. ${ }^{15,17-24}$ However, although various treatments can be combined with bonding mechanisms, there is no specific protocol for treating the zirconia surface before repairing it with composite resin.

Another concern is that in vitro studies addressing the repair of zirconia ceramic restorations are usually performed with Y-TZP with $100 \%$ of the tetragonal phase. However, in the oral environment, under cyclic fatigue loading, thermocycling, and low temperature degradation, the tetragonal phase may be partially transformed into the monoclinic phase, ${ }^{25-31}$ and some changes in the zirconia structure can influence its bonding to resinbased materials. Hydrothermal aging of zirconia can be simulated in a steam autoclave to induce monoclinic phase transformation and is accompanied by changes in some mechanical properties. ${ }^{25,32,33}$

Studies are needed that investigate techniques for repairing Y-TZPs with some monoclinic transformed phases to simulate clinical conditions more closely. Therefore, the purpose of the present study was to evaluate the effect of the monoclinic phase transformed by hydrothermal aging on the shear bond strength (SBS) of a Y-TZP ceramic repaired with composite resin with different surface pretreatments (airborne-particle abrasion and bonding agent). The null hypotheses were that hydrothermally aged Y-TZP ceramic would not exhibit different behavior from unaged Y-TZP and that airborne-particle abrasion and bonding agent conditions (independent variable) would not influence the shear bond strength between the Y-TZP ceramic and the composite resin.

\section{MATERIAL AND METHODS}

For the shear bond strength test, 112 specimens $(7.0 \times 7.0 \times 1.7 \mathrm{~mm})$ were obtained by cutting presintered Y-TZP zirconia ceramic (Lava Zirconia; 3M Dental Products) with a sectioning saw (Isomet 1000; Buehler Ltd) under water cooling. The bonding surface of each specimen was polished with 600- and 1200-grit silicon carbide abrasive papers for 3 minutes each at $400 \mathrm{rpm}$ under wet conditions. The specimens were ultrasonically cleaned (Thornton; Inpec Eletrônica Ltda) in distilled water for 30 seconds and dried with oil-free air. The specimens were sintered in a dedicated oven (Lava Furnac; 3M ESPE AG) according to the manufacturer's instructions. Half of the specimens $(n=56)$ were
Table 1. Materials evaluated

\begin{tabular}{|c|c|c|}
\hline Material & Composition & Manufacturer \\
\hline $50 \mu \mathrm{m} \mathrm{Al}{ }_{2} \mathrm{O}_{3}$ particles & $\mathrm{Al}_{2} \mathrm{O}_{3}>99 \%$ & $\begin{array}{l}\text { Bio-Art Equip } \\
\text { Odontol Ltda }\end{array}$ \\
\hline Rocatec Soft & $30-\mu \mathrm{m}$ silica-modified $\mathrm{Al}_{2} \mathrm{O}_{3}$ particles & $3 M$ ESPE AG \\
\hline $\begin{array}{l}\text { Clearfil SE bond } \\
\text { primer }\end{array}$ & $\begin{array}{l}\text { 10-MDP, HEMA, hydrophilic } \\
\text { dimethacrylate, dl-canphorquinone, } \\
N, N \text {-diethanol- } p \text {-toluidine, water }\end{array}$ & $\begin{array}{l}\text { Kuraray Medical } \\
\text { Inc }\end{array}$ \\
\hline $\begin{array}{l}\text { Clearfil porcelain bond } \\
\text { activator }\end{array}$ & $\begin{array}{l}\text { 3-MPS, hydrophobic aromatic } \\
\text { dimethacrylate }\end{array}$ & $\begin{array}{l}\text { Kuraray Medical } \\
\text { Inc }\end{array}$ \\
\hline RelyX ceramic primer & 3-MPS, ethyl alcohol, water & $\begin{array}{l}3 \mathrm{M} \text { Dental } \\
\text { Products }\end{array}$ \\
\hline RelyX U100 & $\begin{array}{l}\text { Methacrylated phosphoric acid } \\
\text { esters } \\
\text { Triethylene glycol dimethacrylate } \\
\text { Silane-treated silica } \\
\text { Sodium persulfate }\end{array}$ & $3 M$ ESPE AG \\
\hline
\end{tabular}

HEMA, Hydroxyethylmethacrylate; 10-MPS, 10-methacryloyloxydecyl dihydrogen phosphate; 3-MPS, 3-methacryloxypropyl-trimethoxy silane.

Table 2. Description of experimental subgroups

\begin{tabular}{llll}
\hline & Subgroups & $\begin{array}{c}\text { Airborne-Particle } \\
\text { Abrasion }\end{array}$ & \multicolumn{1}{c}{ Bonding Agent } \\
\hline Unaged & ALU-CLE & $\mathrm{Al}_{2} \mathrm{O}_{3}(50 \mu \mathrm{m})$ & $\begin{array}{l}\text { Clearfil SE Bond; primer plus } \\
\text { Clearfil porcelain bond activator }\end{array}$ \\
\hline & ALU-REL & & $\begin{array}{l}\text { RelyX ceramic primer plus } \\
\text { RelyX U100 }\end{array}$ \\
\hline & ROC-CLE & $\begin{array}{l}\text { Rocatec Soft } \\
(30 \mu \mathrm{m})\end{array}$ & $\begin{array}{l}\text { Clearfil SE bond; primer plus } \\
\text { Clearfil porcelain bond activator }\end{array}$ \\
\hline RoC-REL & & $\begin{array}{l}\text { RelyX ceramic primer plus } \\
\text { RelyX U100 }\end{array}$ \\
& ALU-CLE & $\mathrm{Al}_{2} \mathrm{O}_{3}(50 \mu \mathrm{m})$ & $\begin{array}{l}\text { Clearfil SE bond; primer plus } \\
\text { Clearfil porcelain bond activator }\end{array}$ \\
\hline & ALU-REL & & $\begin{array}{l}\text { RelyX ceramic primer plus } \\
\text { RelyX U100 }\end{array}$ \\
& & & $\begin{array}{l}\text { Clearfil SE bond; primer plus } \\
\text { Clearfil porcelain bond activator }\end{array}$ \\
\hline & ROC-CLE & $\begin{array}{l}\text { Rocatec Soft } \\
(30 \mu \mathrm{m})\end{array}$ & $\begin{array}{l}\text { RelyX ceramic primer plus } \\
\text { RelyX U100 }\end{array}$ \\
\hline
\end{tabular}

$\mathrm{ALU}, \mathrm{Al}_{2} \mathrm{O}_{3}$ particles; CLE, Clearfil porcelain bond activator; REL, RelyX U100 adhesive resin cement; ROC, Rocatec soft.

hydrothermally aged in an autoclave (M9 UltraClave; Midmark Corp) at $134^{\circ} \mathrm{C}$ and $300 \mathrm{kPa}$ for 8 hours. ${ }^{25}$

The surface morphology of 1 hydrothermally aged and 1 unaged Y-TZP ceramic specimen was analyzed with scanning electron microscopy (JSM-6610LV; Jeol USA Inc) at $\times 15000$ magnification. The monoclinic and tetragonal phases of 1 aged and 1 unaged Y-TZP ceramic was determined by $\mathrm{X}$-ray diffraction, using a diffractometer (Ultima IV; Rigaku Corp) with "Cu-K $\alpha^{\prime \prime}$ radiation between 27 and 65 degrees, a 0.5 -second per scan point, and a search match program.

Table 1 summarizes the materials used for the SBS test, and the experimental groups are summarized in Table 2. The specimens were airborne-particle abraded with $50-\mu \mathrm{m} \mathrm{Al}_{2} \mathrm{O}_{3}$ (ALU) particles $(\mathrm{n}=28)$ or with tribochemical silica coating with Rocatec Soft (3M ESPE AG) (ROC) $(n=28)$. Airborne-particle abrasion was performed for 15 seconds with an air abrasion unit (Basic Classic; Renfert $\mathrm{GmbH}$ ) at $0.2 \mathrm{MPa}$ air pressure at a 


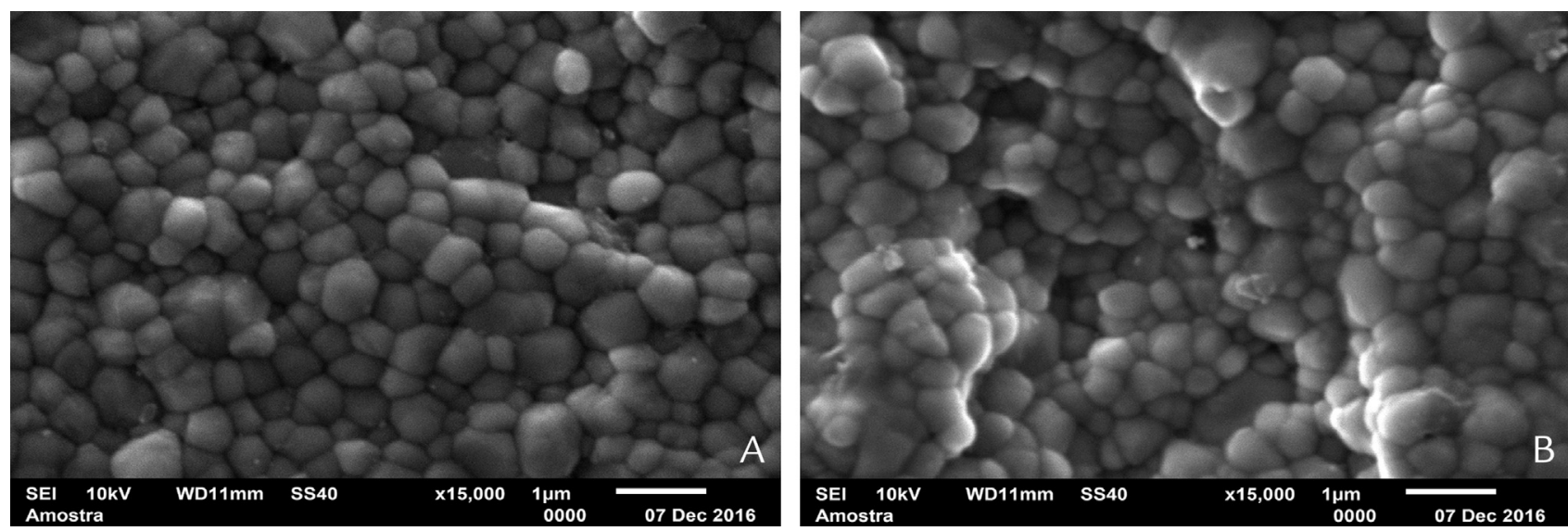

Figure 1. Scanning electron micrographs of $A$, unaged $Y$-TZP and B, aged Y-TZP, showing empty spaces. (Original magnification $\times 11$ 000). Y-TZP, yttrium-tetragonal zirconia polycrystal.

distance of $10 \mathrm{~mm}$ from the surface of the specimen to the abrasion tip. All specimens were cleaned with water for 30 seconds and dried with oil-free air. Next, they received one of the following bonding agents: Clearfil SE Bond PrimerplusClearfil porcelain bond activator (CLE) or RelyX ceramic primer followed by the RelyX U100 adhesive-resin cement. For the CLE groups, 1 drop of each Clearfil SE bond primer and Clearfil porcelain bond activator was mixed and immediately applied to the YTZP surface with a disposable brush tip and left in place for 5 seconds before drying with an oil-free air stream. For the REL groups, the RelyX ceramic primer was applied with a disposable brush tip and left in place for 5 seconds before drying with an oil-free air stream. The RelyX U100 was mixed, a thin layer was applied to the YTZP surface and polymerized (Bluephase; Ivoclar Vivadent AG) for 20 seconds at an intensity of $1200 \mathrm{~mW} / \mathrm{cm}^{2}$.

A custom-made metal split matrix (4-mm internal diameter, 2-mm thickness) was positioned on the treated Y-TZP surface to build a composite resin cylinder. The cavity was filled with composite resin (Filtek Z350 XT A2B; 3M Dental Products), which was then polymerized (Bluephase; Ivoclar Vivadent AG) for 40 seconds.

The specimens were thermocycled (model MSCT-3; Elquip Ltda) between $5^{\circ} \mathrm{C}$ and $55^{\circ} \mathrm{C}$ for 6000 cycles (with a 30-second dwell time in each bath) to simulate 5 years of clinical service. After thermocycling, the zirconia portion of the specimens were embedded in a polyvinyl chloride (PVC) tube with poly(methyl methacrylate) (Jet; Artigos Odontológicos Clássico Ltda), leaving the adhesive interface and the composite resin exposed.

The SBS testing was performed in a mechanical testing machine (EMIC DL2000; EMIC Equipment and Systems Test Ltd) with a 1-kN load cell and a cross-head speed of 0.5 $\mathrm{mm} / \mathrm{min}$. The surface of the tested specimens was analyzed qualitatively, using a stereomicroscope (M80; Leica Microsystems Ltd) with $\times 20$ magnification, and the failure mode was determined as adhesive, cohesive, or mixed.

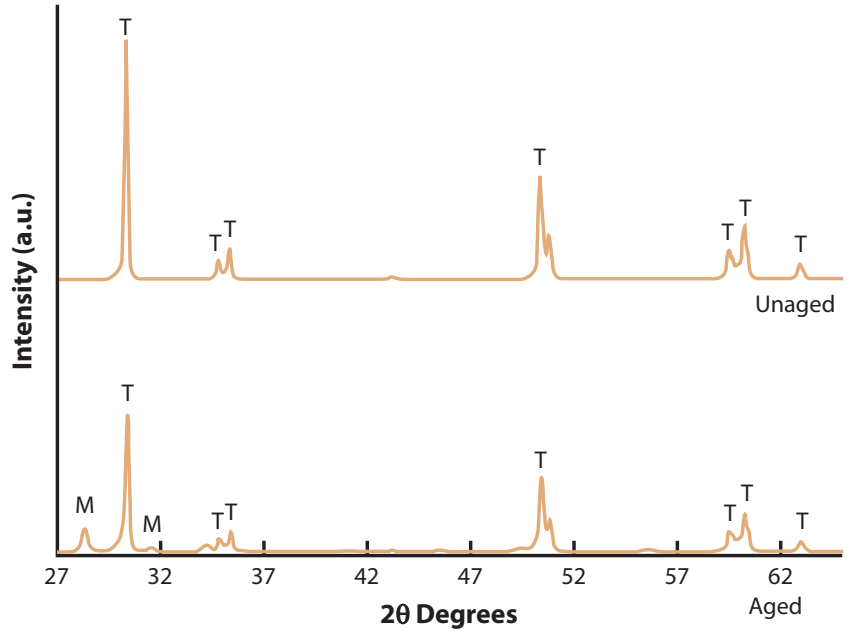

Figure 2. X-ray diffraction of aged and unaged Y-TZP. M, monoclinic phase; $Y$-TZP, yttrium-tetragonal zirconia polycrystal; $T$, tetragonal phase.

Because the original shear bond strength values did not meet the requirements for the parametric tests, the data were transformed to $\log _{10}$. Transformed data were analyzed by 3-way analysis of variance (ANOVA) to test the effect of hydrothermal aging, APA, and bonding agent on the SBS of the zirconia repaired with composite resin. The Tukey honest significant differences post hoc test $(\boldsymbol{\alpha}=.05)$ was applied to determine the difference between the means. Statistical analysis was performed with software (IBM SPSS Statistics v19.0; IBM Corp).

\section{RESULTS}

The unaged Y-TZP showed a quite homogeneous surface (Fig. 1A), whereas the aged Y-TZP zirconia ceramic showed a rougher surface with empty spaces (Fig. 1B). From the X-ray diffraction analysis, only the tetragonal phase was found for the unaged surface, whereas in the aged condition, characteristic peaks of monoclinic and tetragonal phases were observed (Fig. 2). 
Table 3. Three-way analysis of variance

\begin{tabular}{lccccr}
\hline Sources of Variation & $\begin{array}{c}\text { Sum of } \\
\text { Squares }\end{array}$ & $\boldsymbol{d} \boldsymbol{f}$ & $\begin{array}{c}\text { Mean } \\
\text { Square }\end{array}$ & $\boldsymbol{F}$ & $\boldsymbol{P}$ \\
\hline Aging & 0.036 & 1 & 0.036 & 3.386 & .069 \\
\hline APA & 0.614 & 1 & 0.614 & 57.604 & $<.001$ \\
\hline Bonding agent & 0.137 & 1 & 0.137 & 12.814 & .001 \\
\hline Aging $\times$ APA & 0.026 & 1 & 0.026 & 2.394 & .125 \\
\hline Aging $\times$ bonding agent & 0.001 & 1 & 0.001 & 0.070 & .791 \\
\hline APA $\times$ bonding agent & 0.863 & 1 & 0.863 & 80.993 & $<.001$ \\
\hline Aging $\times$ APA $\times$ bonding agent & 0.000 & 1 & 0.000 & 0.030 & .862 \\
\hline Error & 1.108 & 104 & 0.011 & & \\
\hline Total & 69.389 & 112 & & & \\
\hline
\end{tabular}

APA, airborne-particle abrasion.

The 3-way ANOVA for SBS (Table 3) was not significant for hydrothermal aging $(P>.05)$ but it was significant for the APA factors $(P<.001)$ and the bonding agent $(P<.001)$ and their interaction $(P<.001)$. Table 4 shows the mean values, standard deviations, and statistical significance, and Figure 3 shows the interaction plot.

Airborne-particle abrasion did not influence the SBS of the groups bonded with CLE, which assumed an intermediate SBS position. For the groups bonded with REL, the ROC provided higher SBS values than the ALU. The combination ROC-REL provided the highest SBS values, whereas the ALU-REL provided the lowest values. The failure mode was adhesive for all specimens.

\section{DISCUSSION}

Veneer delamination is a common complication in zirconia crowns, ${ }^{1-3}$ and the present study was based on the expectancy that an exposed Y-TZP core would have some monoclinic phase transformation which could alter the adhesion between the ceramic substrate and composite resin repair. The first null hypothesis was accepted, since the partially monoclinic phase transformed Y-TZP by hydrothermal aging did not exhibit different behavior from the unaged Y-TZP.

Previous studies of $Y$-TZP repairs with composite resin were carried out using sintered Y-TZP (with no monoclinic phase). ${ }^{4,5}$ An early transformation from the tetragonal to monoclinic phase in Y-TZP ceramics may occur even during the veneering procedure. ${ }^{27,28}$ Moreover, those Y-TZP zirconia ceramic restorations that need repair have already been in function for some time, and they underwent the initial stages of low-temperature degradation. This phenomenon occurs in the presence of water and at low temperatures and is characterized by a slow transformation of the zirconia grains from the tetragonal to the monoclinic phase, initiating at the surface grains and then later progressing toward the bulk of the material. ${ }^{25}$ This cause-effect relationship, that is, the hydrothermal aging providing phase transformation, which is in accordance with other studies, ${ }^{25,26,29,33}$ is shown in Figure 2.
Table 4. Mean \pm SD shear bond strength values (MPa)

\begin{tabular}{lcccc}
\hline Y-TZP & ALU-CLE & ALU-REL & ROC-CLE & ROC-REL \\
\hline Unaged & $5.90 \pm 1.64^{\mathrm{b}}$ & $4.55 \pm 1.12^{\mathrm{c}}$ & $5.81 \pm 1.20^{\mathrm{b}}$ & $10.19 \pm 2.00^{\mathrm{a}}$ \\
\hline Aged & $5.71 \pm 1.44^{\mathrm{b}}$ & $4.55 \pm 1.24^{\mathrm{c}}$ & $4.99 \pm 1.11^{\mathrm{c}}$ & $8.79 \pm 1.76^{\mathrm{a}}$ \\
\hline
\end{tabular}

$\mathrm{ALU}, \mathrm{Al}_{2} \mathrm{O}_{3}$ particles; CLE, Clearfil porcelain bond activator; REL, RelyX U100 adhesive resin cement; ROC, Rocatec soft. Different superscript lowercase letters indicate significant differences in rows $(P<.05)$.

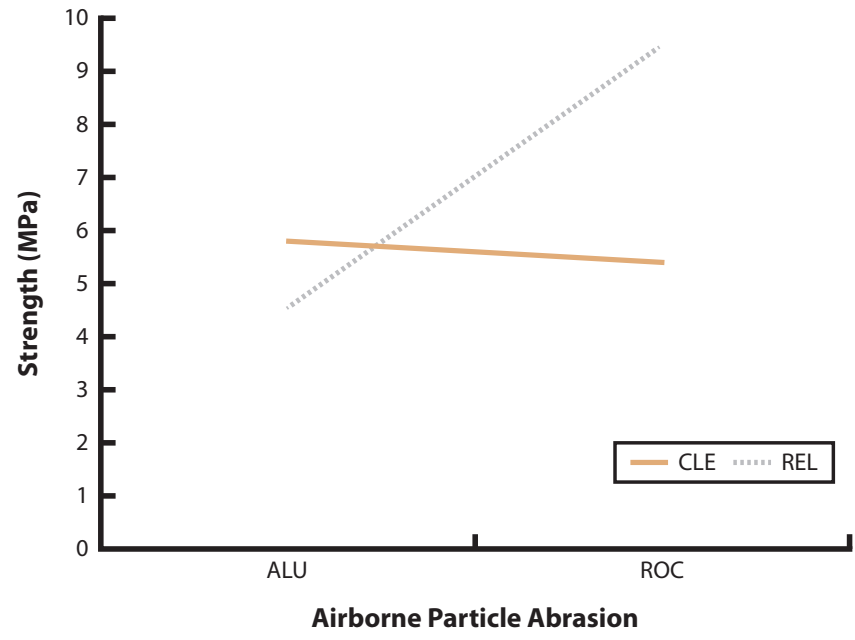

Figure 3. Plot for airborne-particle abrasion-bonding agent interaction.

The tetragonal-to-monoclinic phase transformation resulting from hydrothermal aging occurs within a layer of approximately 6 to $20 \mu \mathrm{m}$ below the zirconia surface, thus changing the morphology, roughness, and texture at the zirconia surface, which could influence the adhesive bonding at the zirconia-composite resin interface. ${ }^{25,30-32}$ Although roughness was not directly measured in the present study, the scanning electron microscopy analysis (Fig. 1) shows a higher roughness of the Y-TZP after aging as a result of elevated grains and the empty spaces left by lost grains. Nevertheless, as with the higher roughness, the aging factor was not significant for SBS testing.

The second null hypothesis that APA conditioning and bonding agents would not influence the shear bond strength at the zirconia-composite resin interface was rejected. The interaction between the APA and bonding agent was significant (Table 4, Fig. 3). The importance of micromechanical retention on the adhesive bonding at the zirconia-composite resin interface was shown in the preliminary study when the specimens that were not airborne-particle abraded, and they spontaneously debonded during the thermocycling. It indicates that the bond strength between the restorative material and bonding agents is highly dependent on micromechanical retention. ${ }^{6,8,23}$

Once micromechanical retention is present, the chemical bond can improve the bond strength between 
the zirconia and resin cement. The CLE groups were treated with Clearfil SE bond PrimerplusClearfil porcelain bond activator, which contains an acidic functional monomer (10-methacryloyloxydecyl dihydrogen phosphate [10-MDP]) and silane (3-methacryloxypropyltrimethoxy silane [3-MPS]), respectively. This composition suggests that the CLE may act as a universal ceramic primer either to oxide-based or silica-based ceramics. ${ }^{33}$ When these bonding agents are used on the zirconia surface treated with $\mathrm{Al}_{2} \mathrm{O}_{3}, 2$ reactions are expected to occur: first, between the 10-MDP and alumina and then between the silane and alumina. When APA is performed using silica-modified $\mathrm{Al}_{2} \mathrm{O}_{3}$ particles, the reactions are between the 10-MDP and silica and between the silane and silica. The reactions between the 10-MDPalumina $^{8-11,15,22}$ and silica-silane ${ }^{17-19}$ are strong and stable. However, the reaction between the silane and alumina provides low bond strength. $8,18,20$ In addition, incompatibility has been reported ${ }^{12,13}$ between the 10-MDP acidic functional monomer and the silica deposited on the zirconia surface by silica coating. Conversely, the use of an MDP-silane agent may produce better results than cement that contains MDP only. The acidic monomers from the MDP hydrolyzes silane coupling agents, increasing the chemical bonds by producing siloxane bonds. ${ }^{24}$ The CLE groups assumed an intermediate position between the ROC-REL (highest SBS) and ALU-REL (lowest SBS).

To understand the significant differences between the ROC-REL and ALU-REL groups, the reactions between the alumina-silane and silica-silane and also between the alumina-phosphoric acid methacrylates present in the RelyX U100 formulation and the silica-phosphoric acid methacrylates should be compared. The superiority of ROC-REL over ALU-REL can be partially justified by the stronger reaction between the silane from the RelyX Ceramic Primer and the silica from the silica-modified $\mathrm{Al}_{2} \mathrm{O}_{3}$ particles (Rocatec Soft) compared with that between the silane and alumina, as discussed earlier. ${ }^{16}$ Regarding the chemical interactions of the zirconia surface with the phosphoric acid methacrylates per se, Nothdurft et $\mathrm{al}^{17}$ found bond strength values of $23.9 \mathrm{MPa}$ when the zirconia was abraded with alumina and of 20.2 $\mathrm{MPa}$ when the surface was silica coated, with no significant difference between these values. Attia ${ }^{31}$ also did not find significant differences between RelyX Unicem and alumina (9.2 MPa) and between this cement and the silica (13.1 MPa). Based on these studies, the reaction between the silane and the abraded substrate determined the significant difference between those 2 groups.

Regarding the comparison between the ALU-CLE and ALU-REL groups, the interaction between the phosphoric acid methacrylates of the RelyX U100 and the alumina resulting from APA provided significantly lower bond strength than that between the 10-MDP monomer from the CLE and alumina; this, as reported earlier, is known to be effective. Gomes et $\mathrm{al}^{9}$ reported that, regardless of the $\mathrm{Al}_{2} \mathrm{O}_{3}$ particle size $(25,50$, or $110 \mu \mathrm{m})$, the alumina-Clearfil ceramic primer (which contains 3-MPS and 10-MDP)-Panavia F (10-MDP) combination provided significantly higher microtensile bond strength than the alumina-Bisfix SE, a self-adhesive resin cement which contains acidic phosphate monomers, similar to RelyX U100. Oyague et $\mathrm{al}^{7}$ also observed higher microtensile bond strength for the alumina-Clearfil ceramic primer (contains 3-MPS and 10-MDP)-Clearfil esthetic cement combination in comparison with the aluminaRelyX Unicem combination.

However, with the ROC-CLE and ROC-REL groups, an opposite situation occurs. Some authors ${ }^{12,14,21}$ have also reported that silica coating-silane-RelyX Unicem resulted in high bond strength values, and, in 2 of these articles, ${ }^{12,14}$ this association promoted significantly higher bond strength than the silica coating-silane-MDP. Although the organophosphate monomer MDP and the phosphate-monomer present in self-adhesive resin cements are both derived from phosphoric acid groups, these monomers react differently with silica.

Although the current study indicated the superiority of some combinations, the maximum bond strength mean value (10.2 MPa) was low. Moreover, analysis of the failure mode revealed $100 \%$ adhesive failure in all groups, indicating that the interface between the materials was the weakest link. Considering that repaired zirconia ceramic restorations are constantly under fatigue load in a moist environment, more efficient bonding techniques and study designs for long-term evaluations are necessary.

\section{CONCLUSIONS}

Within the limitations of this in vitro study, the following conclusions were drawn:

1. Hydrothermal aging did not influence the shear bond strength on the zirconia ceramic-composite resin interface for the evaluated surface treatments (airborne-particle abrasion and bonding agents).

2. The shear bond strength of the composite resin adhesion to the zirconia ceramic was dependent on the airborne-particle abrasion-bonding agent combination.

3. Airborne-particle abrasion with Rocatec Soft followed by a thin layer of RelyX U100 self-adhesive resin cement was the most effective method of repairing zirconia. Conversely, when this cement was applied to the zirconia surface after abrasion with alumina, this procedure provided the lowest bond strength. 


\section{When alumina particles were used for abrasion, repair with Clearfil SE Bond PrimerplusClearfil porcelain bond activator was a better choice.}

\section{REFERENCES}

1. Sailer I, Makarov NA, Thoma DS, Zwahlen M, Pjetursson BE. All-ceramic or metal-ceramic tooth-supported fixed dental prostheses (FDPs)? A systematic review of the survival and complication rates. Part I: Single crowns (SCs) Dent Mater 2015;31:603-23.

2. Al-Amleh B, Lyons K, Swain M. Clinical trials in zirconia: a systematic review. J Oral Rehabil 2010;37:641-52.

3. Schley JS, Heussen N, Reich S, Fischer J, Haselhuhn K, Wolfart S. Survival probability of zirconia-based fixed dental prostheses up to 5 yr: a systematic review of the literature. Eur J Oral Sci 2010:118:443-50.

4. Attia A. Influence of surface treatment and cyclic loading on the durability of repaired all-ceramic crowns. J Appl Oral Sci 2010;18:194-200.

5. Cristoforides P, Amaral R, May LG, Bottino MA, Valandro LF. Composite resin to yttria stabilized tetragonal zirconia polycrystal bonding: comparison of repair methods. Oper Dent 2012;37:263-71.

6. Kulunk S, Kulunk T, Ural C, Kurt M, Baba S. Effect of air abrasion particles on the bond strength of adhesive resin cement to zirconia core. Acta Odontol Scand 2011;69:88-94.

7. Oyague RC, Monticelli F, Toledano M, Osorio E, Ferrari M, Osorio R. In fluence of surface treatments and resin cement selection on bonding to densely-sintered zirconium-oxide ceramic. Dent Mater 2009;25: $172-9$.

8. Yang B, Barloi A, Kern M. Influence of air-abrasion on zirconia cermic bonding using an adhesive composite resin. Dent Mater 2010;26: $44-50$.

9. Gomes AL, Castillo-Oyague R, Lynch CD, Montero J, Albaladejo A. Influence of sandblasting granulometry and resin cement composition on microtensile bond strength to zirconia ceramic for dental prosthetic frameworks. J Dent 2013:41:31-41.

10. Wolfart M, Lehmann F, Wolfart S, Kern M. Durability of the resin bond strength to zirconia ceramic after using different surface conditioning methods. Dent Mater 2007;23:45-50.

11. Blatz MB, Phark JH, Ozer F, Mante FK, Saleh N, Bergler M, et al. In vitro comparative bond strength of contemporary self-adhesive resin cements to zirconium oxide ceramic with and without air-particle abrasion. Clin Oral Investig 2010:14:187-92

12. Baldissara P, Querzè M, Monaco C, Scotti R, Fonseca RG. Efficacy of surface treatments on the bond strength of resin cements to two brands of zirconia ceramic. J Adhes Dent 2013:15:259-67.

13. Fonseca RG, Martins SB, Abi-Rached FO, Cruz CAS. Effect of different airborne-particle abrasion/bonding agent combinations on the bond strength of a resin cement to a base metal alloy. J Prosthet Dent 2012;108: 316-23.

14. Nothdurft FP, Motter PJ, Pospiech PR. Effect of surface treatment on the initial bond strength of different luting cements to zirconium oxide ceramic. Clin Oral Investig 2009:13:229-35.

15. Inokoshi M, Kameyama A, De Munck J, Minakuchi S, Van Meerbeek B. Durable bonding to mechanically and/or chemically pre-treated dental zirconia. J Dent 2013:41:170-9.
16. Chen C, Kleverlaan CJ, Feilzer AJ. Effect of an experimental zirconia-silica coating technique on micro tensile bond strength of zirconia in different priming conditions. Dent Mater 2012;28:e127-34.

17. Blatz MB, Chiche G, Holst S, Sadan A. Influence of surface treatment and simulated aging on bond strengths of luting agents to zirconia. Quintessence Int 2007:38:745-53.

18. Magne P, Paranhos MPG, Burnett LH. New zirconia primer improves bond strength of resin-based cements. Dent Mater 2010;26:345-52.

19. Matinlinna JP, Vallittu PK. Silane based concepts on bonding resin composite to metals. J Contemp Dent Pract 2007;8:1-8.

20. Matinlinna JP, Lassila LV, Vallittu PK. The effect of a novel silane blend system on resin bond strength to silica-coated Ti substrate. J Dent 2006:34:436-43.

21. Attia A. Bond strength of three luting agents to zirconia thermocycling. J Appl Oral Sci 2011;19:388-95

22. Kern M, Wegner SM. Bonding to zirconia ceramic: adhesion methods and their durability. Dent Mater 1998;4:64-71.

23. Kern M. Resin bonding to oxide ceramics for dental restorations. J Adhes Sci Technol 2009;23:1097-111.

24. Thompson JY, Stoner BR, Piascik JR, Smith R. Adhesion/cementation to zirconia and other non-silicate ceramics: Where are we now? Dent Mater 2011;27:71-82.

25. Kohorst $\mathrm{P}$, Borchers L, Strempel J, Stiesch M, Hassel T, Bach FW, et al. Lowtemperature degradation of different zirconia ceramics for dental applications. Acta Biomater 2012;8:1213-20.

26. Borchers L, Stiesch M, Bach FW, Buhl JC, Hubsch C, Kellner T, et al. Influence of hydrothermal and mechanical conditions on the strength of zirconia. Acta Biomater 2010;6:4547-52.

27. Tholey MJ, Swain MV, Thiel N. SEM observations of porcelain Y-TZP interface. Dent Mater 2009:25:857-62.

28. Tholey MJ, Berthold C, Swain MV, Thiel N. XRD2 micro-diffraction analysis of the interface between Y-TZP and veneering porcelain: role of application methods. Dent Mater 2010;26:545-52.

29. Flinn BD, deGroot DA, Mancl LA, Raigrodski AJ. Accelerated aging charac teristics of three yttria-stabilized tetragonal zirconia polycrystalline dental materials. J Prosthet Dent 2012:108:223-30.

30. Kim JW, Covel NS, Guess PC, Rekow ED, Zhang Y. Concerns of hydrothermal degradation in CAD/CAM zirconia. J Dent Res 2010;89:91-5.

31. Muñoz-Tabares JA, Jiménez-Piqué E, Anglada M. Subsurface evaluation of hydrothermal degradation of zirconia. Acta Mater 2011;59: 473-84.

32. Cattani-Lorente M, Scherrer SS, Ammann P, Jobin M, Wiskott A. Low temperature degradation of a Y-TZP dental ceramic. Acta Biomater 2011;7: 858-65.

33. Kim HT, Han JS, Yang JH, Lee JB, Kim SH. The effect of low temperature aging on the mechanical property \& phase stability of Y-TZP ceramics. J Adv Prosthodont 2009;1:113-7.

\section{Corresponding author:}

Dr Gelson Luis Adabo

Department of Dental Materials and Prosthodontics

São Paulo State University (UNESP) School of Dentistry

Rua Humaitá, n 1680 - $4^{\circ}$ andar - sala 415

Araraquara, São Paulo 14801-903

BRAZIL

Email: adabo@foar.unesp.br

Copyright (C) 2017 by the Editorial Council for The Journal of Prosthetic Dentistry. 